\title{
Izquierda y clasismo en los 70. Debates frente al Movimiento de Recuperación Sindical - Lista Marrón del SMATA Córdoba
}

\author{
Rodolfo Laufer
}

Conicet - UBA. Instituto de Historia Argentina y Americana "Dr. Emilio Ravignani" rodolfo.laufer@yahoo.com.ar

En abril de 1972 el Movimiento de Recuperación Sindical (MRS) Lista Marrón encabezado por René Salamanca ganó las elecciones de la seccional cordobesa del Sindicato de Mecánicos y Afines del Transporte Automotor (SMATA). Así, el clasismo llegaba a la conducción de uno de los sindicatos más importantes de Córdoba, cuyos obreros habian protagonizado el Cordobazo de 1969.

El MRS había tenido su punto de inicio hacia mediados de 1970, encabezado por militantes clasistas y agrupando a un amplio abanico de delegados y activistas combativos y opositores a la dirección sindical de Elpidio Torres. Dentro de este, jugaron un rol activo las organizaciones de la izquierda marxista y peronista presentes entre los mecánicos: el Partido Comunista Revolucionario (PCR), el Partido Comunista (PC), el Peronismo de Base (PB), Política Obrera (PO), Vanguardia Comunista (VC), el Partido Revolucionario de los Trabajadores (PRT), El Obrero y Espartaco.

En los últimos años en el ámbito académico se ha producido una revalorización del proceso de radicalización política de los años 60 y 70 , lo que se expresó en el crecimiento de las producciones sobre las experiencias del sindicalismo clasista y sobre las distintas organizaciones de la izquierda. En ese marco, una de las cuentas pendientes más señaladas ha sido la necesidad de profundizar en el análisis de los vínculos entre izquierda y clase obrera (Cangiano, 1993; Basualdo y Lorenz, 2012; Rot, 2016), y en particular sobre la politica de las distintas organizaciones en el ámbito sindical: los mecanismos utilizados para ganar militantes obreros e influencia, las líneas de intervención en los conflictos y en los distintos niveles de las estructuras sindicales, etc. ${ }^{1}$

1. En ese sentido han hecho valiosos aportes trabajos como Pozzi y Schneider (2000), Lorenz (2007), Werner y Aguirre (2009) y Lobbe (2009).

(Archivos, año VI, $\mathrm{n}^{\circ}$ 12, marzo de 2018, pp. 121-141) 
El caso del SMATA Córdoba brinda la posibilidad de avanzar en este camino, observando, en torno a un mismo proceso, las acciones y la linea sindical de una diversidad de fuerzas pocas veces presente en otras experiencias. Si bien los principales estudios sobre el clasismo cordobés que abordaron el caso de los mecánicos (Brennan, 1996; Gordillo, 1996; Mignon, 2014; Ortiz, 2015) repararon en el rol de la izquierda, en general este aspecto no fue estudiado como objeto específico, cuando no directamente subestimado. ${ }^{2}$

Este artículo, por lo tanto, se ubica como parte de una investigación más general, que hace al estudio de la experiencia de los mecánicos de Córdoba, al desarrollo del clasismo y a las opciones políticas y estratégicas adoptadas por esta importante fracción obrera en el marco de un período politicamente signado por el Cordobazo y por el inicio del camino de retirada de la dictadura de la "Revolución Argentina". ${ }^{3}$ En ese sentido, aquí el foco está puesto en el análisis de las distintas organizaciones de la izquierda que tuvieron intervención en el SMATA cordobés, precisando sus origenes, su influencia y el rol que jugaron en las luchas del periodo 1969-1972, y en el proceso de conformación del MRS-Lista Marrón, observando los posicionamientos y debates de las distintas fuerzas que lo integraron.

La principal hipótesis que planteamos es que no se puede comprender adecuadamente la experiencia de los mecánicos cordobeses, el desarrollo del clasismo y la construcción de una alternativa de dirección en el SMATA Córdoba sin estudiar en profundidad el rol que jugaron las distintas organizaciones de la izquierda presentes en esta fracción obrera. Y, en cuanto a la Lista Marrón, a diferencia de los autores que la explicaron como una lista "apolítica" o "moderada" con respecto al antecedente de Fiat (Brennan, 1996: 273; Mignon, 2014: 254), sostenemos que la mayor amplitud de su marco de alianzas y definiciones politico-sindicales tuvieron que ver con las particularidades del SMATA y con los balances

2. Para un análisis de la obra de James Brennan y un debate con sus tesis sobre el clasismo cordobés, ver Laufer (2017b).

3. Definimos al sindicalismo clasista como una línea para la acción en el seno de las organizaciones sindicales basada en la combinación de la lucha reivindicativa con la lucha por una transformación de raíz de la sociedad capitalista, y, en tal sentido, fundada en la concepción del antagonismo y la lucha de clases. Sobre esta base, dentro del clasismo setentista convivieron y disputaron distintas orientaciones y vertientes político-ideológicas, que compartieron como rasgos comunes la práctica de una profunda democracia sindical, el choque con las dirigencias sindicales burocráticas y conciliadoras, el desarrollo de formas de confrontación altamente radicalizadas, la lucha por el ejercicio del control obrero de la producción y los esfuerzos de unidad y coordinación con otros sectores obreros y populares. 
críticos que se produjeron en la izquierda tras la represión y caída del proceso clasista en Sitrac-Sitram.

\section{Antecedentes}

A mediados de 1970, cuando se originó el Movimiento de Recuperación Sindical del SMATA Córdoba, la situación de los trabajadores mecánicos era contradictoria. En el año transcurrido desde el Cordobazo se habían producido importantes cambios.

El dirigente sindical peronista Elpidio Torres, cabeza del sindicato desde 1958, estaba en crisis: en septiembre de 1970 debió renunciar a la Secretaria General de la CGT provincial, y seis meses después haria lo mismo con la dirección del SMATA Córdoba. Luego de trece años de construir su hegemonía mediante una política pragmática, sindicalista y burocrática, obteniendo conquistas merced a la combinación de la movilización controlada de las bases y la negociación con el poder, quien fuera apodado "el Vandor cordobés" había entrado en un proceso de declive.

Esto se fue haciendo perceptible desde la instauración de la dictadura de la "Revolución Argentina" en 1966. El Gobierno de Onganía rápidamente fue dejando cada vez menos espacio para la clásica política vandorista de "golpear y negociar", pero a esto se sumó la crisis de la industria automotriz asentada en Córdoba, que produjo el quiebre de las buenas relaciones que Torres había forjado con la patronal de la norteamericana Industrias Kaiser Argentina (IKA) (Gordillo, 1996: 140; Brennan, 1996: 147). Poco después, esta fue adquirida por el monopolio francés Renault, iniciándose una restructuración tecnológica que, ante la pasividad sindical, afectó fuertemente las condiciones de trabajo en las plantas. En 1967 la dirección nacional del SMATA a cargo de Dirck Kloosterman intervino la seccional cordobesa (Gordillo, 1996: 174; Campellone y Arriola, 2006: 103), y, si bien la mayoría de los mecánicos rechazaron la intromisión porteña, las denuncias de maniobras fraudulentas, persecución a la oposición y corrupción contribuyeron al deterioro de la imagen de Torres. Ese mismo año surgió la Lista Azul, una lista muy heterogénea que agrupaba a sectores peronistas, radicales, de izquierda e independientes, que en 1968 se alinearia con la CGT de los Argentinos (CGT-A) conducida por Raimundo Ongaro. ${ }^{4}$ El propio surgimiento de la CGT-A fue una complicación más, ya que

4. Entrevistas a Livio Palacios, Rafael Solís y Juan Delgado hechas por el autor, agosto de 2015. Los tres entrevistados fueron miembros de la Lista Azul y luego de la Lista Marrón. Palacios fue el referente en el SMATA Córdoba del Movimiento Obrero Radical y Juan Delgado, del Peronismo de Base. 
mientras que la mayoría de los gremios de Córdoba se alinearon allí, Torres mantuvo al SMATA al margen de ambas centrales, aunque inclinado hacia el vandorismo, lo que le valió fuertes críticas plasmadas en el semanario nacional de la CGTA. ${ }^{5}$ A su vez, en Perdriel, la planta de matrices de IKA, se fue gestando un proceso de movilización y participación democrática de los obreros que desembocó en el reemplazo de los delegados de Torres por una nueva dirección, los "activistas de Perdriel" encabezados por Agustín Funes, transformando a la planta en un bastión opositor (Laufer, 2016: 97). ${ }^{6}$

El otro cambio tenía que ver con el desarrollo de una alternativa a la conducción torrista. A pesar de que el mismo Torres planteó que él siempre había significado "una muralla para la oposición de izquierda" (Torres, 1999: 147), nunca pudo evitar que hubiera "una oposición de izquierda siempre presente en el sindicato" (Gordillo, 1996: 226). Miembros del PC habían formado parte de la primera conducción del SMATA Córdoba tras el golpe de 1955, con el sindicalismo peronista proscripto (Brennan, 1996: 85; Gordillo, 1996: 64), y luego del triunfo de Torres el activismo comunista y el Movimiento de Unidad y Coordinación Sindical (MUCS) que impulsaba mantuvieron siempre una fuerza importante (Bergstein, ${ }^{7}$ 1987: 42; Ferrero, 2009: 122). A esto se sumó a inicios de la década del 60 la aparición de la Fracción Trotskista de Obreros Mecánicos, impulsada por un núcleo de militantes del Partido Obrero Revolucionario (POR), que llegó a conformar la Lista Rosa para las elecciones de 1962, aunque esta finalmente fue proscripta y sus referentes detenidos y despedidos ${ }^{8}$ (Gordillo, 1996: 223; Menéndez, 2009).

Pero fue en la segunda mitad de los 60 , al compás de la política de la dictadura de Onganía, del debilitamiento del torrismo y de la radicalización general, cuando la izquierda cobró un nuevo impulso entre los mecánicos. Así, las nuevas tendencias de la izquierda revolucionaria empezaron a trabar vínculos con activistas obreros del SMATA y a insertar militantes en las fábricas.

Cuando en 1965 nació el PRT, este ya tenía militantes entre los

\footnotetext{
5. "SMATA", Periódico CGTA, nº 7, junio de 1968, p. 3.

6. Miguel Salinas [seudónimo de Agustín Funes], "Perdriel, Córdoba: Testimonio de una experiencia del movimiento obrero", Teoría y Política, $\mathrm{n}^{\circ} 11$, septiembre-octubre de 1973.

7. Jorge Bergstein fue el Secretario General del PC de Córdoba desde 1969 hasta 1975.

8. Entrevista a Héctor Menéndez hecha por el autor, agosto de 2015. Menéndez fue el principal dirigente del POR en el SMATA Córdoba, y quien encabezó la Lista Rosa.
} 
mecánicos ${ }^{9}$ (Bohoslavsky, ${ }^{10}$ 2011: 27, 29). Tras la fractura partidaria en 1968, la totalidad de sus miembros en Córdoba se alinearon con el PRT-El Combatiente, manteniendo algunos contactos en el SMATA, pero durante este período aún era escaso el desarrollo de una línea partidaria específica para el ámbito sindical. ${ }^{11}$ El PCR, surgido como ruptura del PC en 1967, rápidamente se estructuró en la provincia, donde dio impulso a la conformación de las Agrupaciones $1^{\circ}$ de Mayo en el movimiento obrero, conformó una célula en IKA-Santa Isabel y, sobre todo, logró vincularse y finalmente incorporar a los principales referentes de los "activistas de Perdriel"12 (Laufer, 2016: 97-98). Al mismo tiempo, sumó también a varios integrantes de la agrupación Felipe Vallese, que tenía trabajo en estatales y metalúrgicos, entre ellos a René Salamanca (Sánchez, 2008: 84). En el caso de Política Obrera, un grupo de militantes partidarios se instaló en Córdoba en 1967, consiguiendo entrar como obreros en Thompson Ramco y otras fábricas. ${ }^{13} \mathrm{~A}$ partir de esto, el partido conformó la agrupación Vanguardia Obrera Mecánica (VOM) y logró ganar algunos delegados. ${ }^{14}$

En cuanto al Partido Comunista, merced a su posicionamiento opositor a Onganía y la integración del MUCS en la CGT-A, también se fortaleció en este período (Bergstein, 1987: 43). Pero, al mismo tiempo, tuvo que enfrentar la aparición de esta nueva izquierda que lo calificaba de reformista, pacifista y criticaba su subordinación a la URSS. Como veremos, su condena en bloque a todas estas nuevas fuerzas, a las que caracterizaba como "ultraizquierda", sus reticencias frente a la nueva corriente sindical clasista en conformación y su política oscilante

9. Para este periodo nos referimos al PRT surgido de la fusión de Palabra Obrera y el Frente Revolucionario Indoamericano Popular (FRIP). Ya en los primeros números del periódico partidario La Verdad se encuentran notas específicas sobre el SMATA Córdoba. Ver por ejemplo "Córdoba", La Verdad, n 7, 30 de agosto de 1965, p. 8.

10. Bohoslavsky fue militante estudiantil y sindical del PRT-ERP de Córdoba.

11. Pablo Pozzi utiliza justamente dos ejemplos de Córdoba para concluir que, todavía en 1971, "los cuadros del PRT-ERP, la mayoría con escasa experiencia, estaban buscando las formas más adecuadas de combinar la lucha armada con el trabajo sindical y reivindicativo" (2004: 177).

12. "Balance de la zona Córdoba", Comité Zonal PCR Córdoba, mimeo, circa fines 1971.

13. Entrevista a Christian Rath hecha por el autor, 20 de octubre de 2014. Rath fue la cabeza de este grupo de militantes de PO en el SMATA.

14. Una nota publicada en el periódico partidario en agosto de 1968 ya muestra un conocimiento interno del SMATA Córdoba. "Córdoba. La lucha de los obreros de Kaiser”, Política Obrera, n 34, 5 de agosto de 1968. 
en relación al torrismo, ${ }^{15}$ lo irian dejando en gran medida a la zaga del proceso de radicalización obrera.

El Cordobazo de 1969 marcó un antes y un después en la experiencia de los mecánicos, que fueron quienes el 29 de mayo aportaron el principal contingente obrero en las calles. La represión y el asesinato de Máximo Mena desató el estallido popular generalizado con un alto grado de radicalización, que incluyó el enfrentamiento de las fuerzas policiales, la erección de barricadas, la ocupación de barrios enteros y la destrucción de símbolos del poder económico y político (Balvé et al., 2006: 157-204). Los distintos grupos de la izquierda que militaban en los mecánicos, aún pequeños, participaron activamente de la pueblada (Laufer, 2016: 99-100). Los hechos desbordaron las intenciones de Torres y en general de toda la dirigencia sindical, y el secretario del SMATA fue detenido y mantenido en prisión durante seis meses (Brennan, 1996: 198). La rebelión obrera, estudiantil y popular de Córdoba condensó los reclamos reivindicativos con el rechazo al autoritarismo y la opresión dictatorial, hirió de muerte al proyecto de la "Revolución Argentina" y abrió un período de ascenso de la movilización social y la radicalización política que influyó intensamente en los mecánicos.

Luego del Cordobazo, nuevas organizaciones de izquierda se hicieron presentes en el SMATA. Un sector peronista combativo que integraba la Lista Azul formó parte, junto con obreros de Fiat y sectores de militancia barrial y estudiantil, de la conformación del Peronismo de Base provincial, que reivindicaba el clasismo y se vincularía a las Fuerzas Armadas Peronistas (FAP) ${ }^{16}$ (Duhalde y Pérez, 2003: 63). También aparecieron activistas de El Obrero, ${ }^{17}$ que había nacido poco antes en Córdoba por iniciativa de un grupo de militantes provenientes del Movimiento de Liberación Nacional (MLN) (Cormick, 2014). Este editaba un boletín para las fábricas automotrices con un fuerte contenido propagandístico y de educación ideológica, y en 1970 ya tenía algunos activistas y contactos entre los mecánicos. ${ }^{18} \mathrm{~A}$ su vez, si bien en este período no contó con militantes entre los mecánicos, el Partido Revolucionario de los Trabajadores-La Verdad (PRT-LV) inició una activa política de in-

15. Por ejemplo, la CGTA denunció que el MUCS apoyó a la lista Verde y Celeste de Torres en la elección de delegados congresales del SMATA Córdoba de diciembre de 1969. "Córdoba: El MUCS ayuda a Elpidio", Periódico CGTA, n 55, febrero de 1970, p. 7.

16. Entrevista a Juan Delgado, ya citada.

17. El Obrero fue uno de los núcleos principales que posteriormente dio origen a la Organización Comunista Poder Obrero (OCPO).

18. Entrevista a Dardo Castro hecha por el autor, mayo de 2015. Castro fue uno de los principales dirigentes de El Obrero. 
serción, mandando a la provincia a inicios de 1970 a Orlando Matolini, ex dirigente de Citroën en Buenos Aires ${ }^{19}$ (González, 2006: 287-291).

Tras su liberación, en marzo de 1970 Elpidio Torres fue designado Secretario General de la CGT cordobesa, pero ya estaba abierto en la provincia un proceso de "irrupción de las bases sobre los dirigentes" (Brennan y Gordillo, 2008: 111). Ese mismo mes se inició la experiencia clasista en los sindicatos de fábrica de Concord y Materfer de Fiat, Sitrac y Sitram, con la destitución de las direcciones sindicales pro patronales y la imposición de nuevos líderes que encabezaron un proceso de lucha y democracia sindical inédito, con gran repercusión en Córdoba y en todo el país (Brennan 1996: 218; Mignon, 2014: 147-152).

En el SMATA, el primer estallido se produjo en Perdriel. El 12 de mayo, sus trabajadores resolvieron en asamblea la ocupación de la fábrica en contra del traslado, acordado por el torrismo y la patronal, de los referentes que se perfilaban como delegados opositores, vinculados a la Agrupación $1^{\circ}$ de Mayo y al PCR (Laufer, 2016: 101-111). La planta fue rodeada con tanques de nafta para impedir el desalojo y 38 directivos quedaron como rehenes. A pesar de que Torres planteó su oposición a la medida, con la extensión de la solidaridad entre las bases del SMATA y de todo Córdoba, al tercer día de toma se obtuvo un triunfo contundente, revirtiendo los traslados y logrando la elección de los delegados.

Poco después, ante el primer aniversario del Cordobazo y la discusión de los convenios, el Cuerpo de Delegados del SMATA siguió el ejemplo de Perdriel y resolvió ocupar todos los establecimientos el 2 de junio (Mignon, 2014: 187-199; Laufer, 2017a: 131-137). Fueron tomadas las plantas de Santa Isabel, Perdriel, ILASA, Transax, Thompson Ramco y Grandes Motores Diesel, y al día siguiente se les sumaron Fiat Concord, Fiat Materfer y Perkins. Los directivos retenidos como rehenes llegaron a 700 , nuevamente se rodearon las plantas con tanques de combustible, se electrificaron las rejas y se prepararon bombas molotov para resistir. El 4 de junio, Perdriel fue desalojada con una violenta represión, y el resto de las fábricas abandonarian las ocupaciones a propuesta del torrismo y algunos de los dirigentes de la Lista Azul. A partir de alli se inició la llamada "huelga larga", con asambleas y paros que se extendieron durante un mes. El desprestigio de Torres llevó a la conformación de la "Comisión de Acción y Lucha", integrada por activistas del sector combativo de la Lista Azul, del MUCS y de VOM, ${ }^{20}$ que jugó un papel fundamental en el

19. Entrevista a Orlando Matolini hecha por el autor, noviembre de 2015. El PRT-LV tenía una importante experiencia entre los obreros automotrices de Buenos Aires, donde habia logrado dirigir las comisiones internas de Citroën y Chrysler (Mangiantini, 2014: 46-48).

20. La $1^{\circ}$ de Mayo, con sus principales referentes de Perdriel presos, quedó excluida, 
sostenimiento de la huelga. Esta finalmente sería quebrada el 6 de julio: violando la resolución de la última asamblea, el torrismo organizó un grupo de 500 obreros que en colectivos de la empresa ingresaron a las fábricas, y la Comisión Directiva dio por finalizadas las medidas. En los dias siguientes Torres se abocó a negociar los despidos, que totalizaron unos 700, entre ellos la mayoría de los referentes de la Lista Azul, que quedó desarticulada, y los activistas clasistas y opositores como Agustín Funes del PCR y Cristian Rath de PO.

Durante la "huelga larga" también hizo su aparición Vanguardia Comunista. Aún sin militantes en el SMATA, acompañó el conflicto desde sus activistas en la ciudad, y dedicó el primer número del boletín de su agrupación sindical a un largo balance de la lucha mecánica. ${ }^{21}$ Tras el fin del conflicto, entró a la planta de Transax Roberto Nágera, quien fue el principal referente de VC entre los mecánicos. ${ }^{22}$ También en este momento se organizó en la planta de Fiat Grandes Motores Diesel (GMD), cuyos obreros estaban afiliados al SMATA, el grupo Espartaco, proveniente de otra fracción del MLN (Pacheco, 2013: 182). También en este caso el primer número de su publicación, Bandera Roja, analizó extensamente el conflicto de los mecánicos. ${ }^{23}$

Así estaba configurada entonces la situación en la segunda mitad de 1970, cuando se origina el MRS. Con los 700 despidos, Torres había logrado descabezar a la oposición y las corrientes clasistas, pero en ello había gastado sus últimas salvas: la derrota de la huelga señaló su derrumbe gremial y político, y en los meses siguientes deberia abandonar todos sus cargos. Por otra parte, en el espacio opositor se produciria un acelerado proceso de reorganización para construir una alternativa efectiva a la dirección torrista en descomposición.

\section{E1 MRS y la Lista Marrón: posiciones y debates en la izquierda}

A pesar de los despidos y de la ofensiva patronal en las plantas, en el SMATA pronto comenzaron a reagruparse y organizarse de manera clandestina los activistas clasistas y opositores que habían quedado,

\footnotetext{
y sería muy crítica de rol de esa comisión. Ver "Las luchas cordobesas", Nueva Hora, $\mathrm{n}^{\circ} 48,2$ a. quincena de julio de 1970, p. 4.

21. Cordobazo, Organizadores de Comisiones Obreras de Córdoba, año 1, n ${ }^{\circ} 1,20$ de agosto de 1970.

22. Entrevista a Roberto Nágera hecha por el autor, agosto de 2015.

23. Bandera Roja, año 1, n 1, Córdoba, agosto de 1970.
} 
conformando una Coordinadora. ${ }^{24} \mathrm{Al}$ principio esta no era más que una reunión de unos 15 o 20 obreros, muy pocos de ellos delegados, y participaban miembros de la Agrupación $1^{\circ}$ de Mayo, el Peronismo de Base, el MUCS, Vanguardia Obrera Mecánica y El Obrero, junto a activistas sindicales peronistas, radicales e independientes sueltos, provenientes de la ex Lista Azul o que habían roto con el torrismo.

La primera tarea que se propusieron fue la reconstrucción del cuerpo de delegados y las comisiones internas, desplazando a los referentes del torrismo. Los rápidos éxitos en esta tarea fueron afirmando la idea de que era posible trabajar para la recuperación sindical, lo que se plasmó en el cambio de nombre: nacía así el Movimiento de Recuperación Sindical (MRS). Ya en 1971 este comenzó a plantearse en los hechos como una dirección alternativa, apareciendo algunos de sus integrantes de manera pública e impulsando y encabezando acciones de lucha que desbordaban a la conducción sindical. En enero, el MRS presentó una lista en las elecciones de Comisión Interna de Reclamos de Santa Isabel: el escandaloso fraude al que tuvo que apelar el torrismo evidenciaba que esta había pasado a estar en minoria en la fábrica más grande y corazón del SMATA. ${ }^{25}$

El reemplazo de Torres, Mario Bagué, asumió en marzo intentando mostrarse como un cambio, con un discurso más radicalizado y alineándose con el ala sindical peronista que dirigía Atilio López en la provincia. Pero a poco andar se demostró que no era más que una continuidad devaluada del torrismo, directamente subordinada a la dirección nacional del SMATA (Brennan, 1996: 275).

Al calor del proceso de reorganización obrera, y dada la heterogeneidad de perspectivas y fuerzas politicas presentes en el MRS, una serie de debates fueron jalonando su trayectoria, en un momento político teñido por el lanzamiento del Gran Acuerdo Nacional (GAN) por parte de Lanusse, que intentaba dividir y poner un freno a la radicalización política y el auge revolucionario combinando la represión con la perspectiva de una apertura electoral.

Los primeros debates se dieron en torno a la experiencia clasista en Fiat y sus definiciones sindicales y politicas. Este proceso era seguido con gran atención por el activismo clasista del SMATA, que procuraba sumar a los mecánicos a las distintas luchas e iniciativas impulsadas desde estos sindicatos, como la toma de Concord en enero de 1971 y el "Viborazo" que dos meses después echó por tierra las intenciones del

24. Ricardo Fierro y Pablo Reartes [seudónimo de René Salamanca], "Reflexiones sobre la historia de los mecánicos de Córdoba”, Teoría y Política, n 11 , septiembre-octubre de 1973 , p. $31,36$.

25. Ibídem, p. 38. 
nuevo interventor de la provincia, José Camilo Uriburu, de cortar "la venenosa serpiente" anidada en Córdoba (Balvé et al., 2006: 79-125). A su vez, en mayo, los sindicatos de Fiat presentaron en el Plenario Nacional de Gremios Combativos convocado por la CGT cordobesa una propuesta de programa planteada como las "bases programáticas del movimiento obrero clasista", que convocaba a barrer a "las direcciones sindicales al servicio del régimen y del sistema" y se pronunciaba por la liberación social y nacional y el socialismo. ${ }^{26} \mathrm{Y}$ en agosto realizaron un "Congreso Nacional de sindicatos combativos, agrupaciones clasistas y obreros revolucionarios" que, tras intensas polémicas, finalizó con una declaración en la que se planteaba la tarea de "crear el verdadero sindicalismo clasista y revolucionario" y el objetivo de "la destrucción definitiva del capitalismo, y por ende de su fase superior, el imperialismo, y por la construcción del socialismo", adoptando la consigna "Ni golpe ni elección, revolución" y pronunciándose contra el GAN, La Hora del Pueblo y el Encuentro Nacional de los Argentinos (ENA). ${ }^{27}$

El debate en el MRS se desencadenó cuando algunos de sus integrantes, en particular el PCR, VC y El Obrero, propusieron que el Movimiento se definiera en el mismo sentido que Fiat:

Las discusiones en el MRS serán: apoyo o no al programa de FIAT y al Congreso citado por sus sindicatos; denuncia o no del GAN (y sus "apoyaturas” la Hora del Pueblo y el Encuentro de los Argentinos) y definición como clasista o como combativo. ${ }^{28}$

Todos los grupos de izquierda que tenían presencia en el SMATA (PCR, PB, PRT, PO, VC, El Obrero y Espartaco), salvo el PC, entendían al GAN y la convocatoria a elecciones como una trampa, y terminarian llamando a boicotear, votar en blanco o abstenerse en marzo de $1973 .^{29}$ A su vez, la cuestión de la definición como "clasista" o "combativo" plan-

26. "Sitrac-Sitram a los trabajadores y al pueblo argentino", 22 de mayo de 1971, Archivo Sitrac/Carpeta1/Doc17.

27. "Plan de lucha aprobado en el plenario convocado por Sitrac-Sitram", 28 de agosto de 1971, Archivo Sitrac/CarpetaD/Doc91.

28. Fierro y Reartes, op. cit.: 40.

29. Si bien en el Peronismo de Base a nivel nacional predominó la postura de voto crítico al FREJULI, en la regional cordobesa era fuerte la postura votoblanquista, por lo que se dejó en libertad de acción (Duhalde y Pérez, 2003: 90-91). Aunque PO compartía la postura contra el GAN, en ese momento VOM rechazó la necesidad de que el MRS planteara "el repudio a la Hora y al ENA porque ello hubiera imposibilitado un frente cuyo objetivo era derrotar a la burocracia y recuperar la democracia sindical como método para elaborar la definición política de la clase obrera". "Triunfo histórico en el SMATA cordobés", Política Obrera, n 108, 3 de mayo de 1972, p. 7. 
teaba el alineamiento que tendría el MRS respecto de las corrientes del movimiento obrero cordobés: con los clasistas de Fiat, o con la alianza de Atilio López (sindicalismo peronista legalista) y Agustín Tosco (gremios independientes) que desde abril encabezaba la CGT Córdoba. El triunfo de las posiciones más radicalizadas en la "mesa chica" del Movimiento llevó a que en ese momento los militantes y activistas vinculados al PC se retiraran del MRS. ${ }^{30}$ El Partido Comunista integraba el ENA, era parte de los gremios independientes de Córdoba, y desde el inicio había recelado de la línea impulsada por los dirigentes de Fiat, a los que etiquetaba como divisionistas, "de signo ultraizquierdista, verbalista, frecuentemente anticomunista". ${ }^{31}$

La represión y disolución de Sitrac-Sitram en octubre de 1971 (Brennan, 1996: 249-252; Mignon, 2014: 230-233) fue otro momento clave para el MRS. En toda la izquierda se abrió un proceso de análisis y debate en torno a las lecciones de esta experiencia, y, si bien el Movimiento no logró realizar un balance en común, esto tuvo impacto en el proceso de los mecánicos. En líneas generales, entre las fuerzas de izquierda que tenian presencia en el SMATA se configuraron tres posicionamientos sobre Sitrac-Sitram. El PC lo criticó duramente, planteando directamente que había sido una experiencia que "en los hechos perjudicó a los trabajadores del complejo FIAT, al movimiento obrero cordobés y a los intereses de la clase obrera del país". ${ }^{32}$ El PRT, VC, el PCR, el PB y PO, con sus matices y diferencias, hicieron un análisis crítico. Partiendo de una reivindicación general de la experiencia, plantearon cuestionamientos, entre otras cosas, a la confusión entre organización sindical y partido revolucionario, a cierta separación de las direcciones respecto de las bases, al aislamiento en relación con el resto del movimiento obrero de Córdoba y a la falta de una respuesta efectiva ante la ofensiva represiva. ${ }^{33}$ Por último, los grupos cordobeses

30. "El triunfo del MRS en el SMATA cordobés", Nueva Hora, n 92, 1era quincena de junio de 1972.

31. La Mulita. Periódico de los trabajadores comunistas de Fiat, septiembre de 1971, p. 3.

32. “¿Clasismo o aventurerismo? Sitrac-Sitram. Experiencias y enseñanzas”, Partido Comunista, agosto de 1972.

33. Ver, entre otras fuentes: "Desde Córdoba: Balance del movimiento clasista", El Combatiente, $\mathrm{n}^{\circ}$ 65, 19 de diciembre de 1971; "El Maoísta. Boletín de los militantes de VC de Fiat", $\mathrm{n}^{\circ}$ 2, enero de 1972; "Comandismo, una línea de derrota", Comité Central PCR, 30 de noviembre de 1971; "Las enseñanzas del año que pasó", Evita, Órgano de difusión Peronismo de Base Regional Córdoba, $\mathrm{n}^{\circ}$ 10, febrero de 1972; "Defender a Sitrac-Sitram", Política Obrera, n 98, 10 de noviembre de 1971. También al PRT-LV correspondería incluirlo entre los que realizaron un balance crítico (González, 2006: 523-531). 
El Obrero y Espartaco fueron quienes más se embanderaron en una defensa casi irrestricta de la experiencia y la línea de Fiat. ${ }^{34}$

Las consecuencias prácticas de los distintos balances del proceso de Fiat se verían en la polémica en torno a la conformación de la Lista Marrón en el SMATA. Así, ante la convocatoria a las elecciones del SMATA cordobés para abril de 1972, la mayoría de las fuerzas del MRS procurarán ampliar el marco de alianzas contra el torrismo y no forzar definiciones que vayan por delante del proceso de las bases. ${ }^{35}$

Esto se vio en particular en el PCR y VC, que, como vimos, previamente habian sido dos de las organizaciones que impulsaron las definiciones políticas y programáticas del MRS. ${ }^{36}$ En la Conferencia Regional del PCR de Córdoba, realizada a fines de 1971, se definió al MRS del SMATA como "un camino original",

que resuelve correctamente los errores de FIAT y alumbra una línea para la recuperación de las organizaciones sindicales a través del frente único de las fuerzas avanzadas, particularmente peronistas y comunistas revolucionarios, en cuyo seno la disputa por la hegemonía es una cuestión viva, práctica, y que atiende al desarrollo real de la conciencia de clase, fundamentalmente a la experiencia realizada. ${ }^{37}$

34. "Acerca de Sitrac-Sitram", El Obrero, 26 de octubre de 1971; "Sitrac-Sitram. Responder al golpe reorganizando las fuerzas clasistas", Espartaco, 16 de noviembre de 1971.

35. Ortiz registra este cambio en las experiencias del clasismo cordobés, formulándolo de la manera siguiente: "Luego de la disolución de los sindicatos de FIAT en Córdoba, los clasistas fueron ampliando las distancias con la idea de "vanguardia obrera" que ligaba al sindicato con la función del partido político revolucionario. A pesar de la heterogeneidad de experiencias clasistas durante el período 1972-1974, una de las constantes fue la búsqueda de una política frentista, pensando al sindicato como un espacio de identidad colectiva diversa que cristalizó en numerosos Movimientos de Recuperación Sindical" (Ortiz, 2015: 240).

36. Política Obrera señaló este cambio en la política del PCR del SMATA a partir del balance de Fiat: "Sólo porque este balance existió es que un sector de la ultraizquierda, la $1^{\circ}$ de Mayo, pegó un viraje de $180^{\circ}$ estructurando un frente con VOM, con el MUCS y con el Peronismo combativo" ("Triunfo histórico en el SMATA cordobés", Politica Obrera, $\mathrm{n}^{\circ}$ 108, 3 de mayo de 1972, p. 6).

37. Fierro y Reartes, op. cit., p. 41. Las conclusiones de la experiencia del SMATA cordobés quedarian luego plasmadas en las resoluciones del Segundo Congreso partidario: "El centro de la Agrupación es la lucha por reconquistar el sindicato para el clasismo revolucionario; lucha en la que busca términos de acuerdo con los delegados y activistas que representan a esas masas en lucha por expulsar a los jerarcas y traidores de los gremios, como es el caso de los Movimientos de Recuperación Sindical. En el desarrollo y construcción de esos acuerdos de frente único, las Agrupaciones clasistas establecen una pugna abierta por la dirección del gremio para el clasismo 
En el mismo sentido, VC sostuvo:

los activistas revolucionarios que trabajamos en la Marrón, entre los que nos contamos, sacamos experiencias de los errores cometidos en el pasado. Se dejó de lado la subestimación de las elecciones como una instancia más -no la principal-en el enfrentamiento antiburocrático. Se abandonó el sectarismo programático, que intentaba dividir aguas desde el inicio con las corrientes reformistas, sin tener en cuenta el nivel de conciencia alcanzado por la vanguardia y las masas. ${ }^{38}$

A diferencia de esto, El Obrero persistió en su política previa, planteando ahora el boicot a las elecciones sindicales. Más tarde, en tono autocrítico, sostendrían:

Planteando una posición superizquierdista frente a las futuras elecciones del gremio [...] planteábamos que había que impulsar el boicot por tramposas y como alternativa concreta una dirección surgida por asamblea. ${ }^{39}$

El debate se dirimió en diciembre de 1971, cuando el MRS organizó una asamblea-asado en el local del Sindicato de Petroleros Privados en la que participaron 70 obreros, 30 de los cuales eran delegados de sección. ${ }^{40}$ Con un informe a cargo de Salamanca, allí se tomó la decisión de constituir la Lista Marrón.

Fuertemente aislado, El Obrero haría una última intervención en marzo de 1972, abandonando su posición de boicot, pero exigiendo la adscripción del MRS a las resoluciones del Congreso de Sitrac-Sitram. ${ }^{41}$

revolucionario". "Documentos aprobados por el Segundo Congreso del Partido Comunista Revolucionario", 7, 8 y 9 de abril de 1972, en Documentos aprobados por el PCR desde su $1^{\circ}$ Congreso, diciembre de 1969, hasta su $2^{\circ}$ Congreso, abril de 1972, Publicaciones $35^{\circ}$ aniversario del PCR, tomo 2, p. 203.

38. "El triunfo de la Marrón en el SMATA cordobés", No Transar, n 110, p. 7.

39. "Informe de la célula de Kaiser sobre su participación en el MRS y el proceso eleccionario", El Obrero, 8 de marzo de 1972, p. 2. Sostiene Cormick en relación a la posición de $\mathrm{El}$ Obrero en el SMATA Córdoba: "Consecuentes con su práctica previa, los militantes de El Obrero subestimaron las posibilidades y potencialidades de la recuperación sindical y se orientaron con fuerza a la disputa ideológica con el reformismo" (2014: 9).

40. Fierro y Reartes, op. cit., p. 41.

41. "Recién en marzo la c. [célula] advierte sus desviaciones; a raíz de charlas con PO se rediscute el boicot y se discute una posición que sitúa las elecciones en su justo lugar -no constituyen en sí mismas un método burocrático, y deben ser instrumen- 
Nuevamente derrotado, se retiró definitivamente del MRS y, junto con Espartaco constituyó el "Núcleo de Activistas Clasistas del SMATA", que llamaría a un "voto crítico" a la Lista Marrón, cuestionando "su actitud oportunista y vacilante". ${ }^{42}$

El Peronismo de Base se dividió: un sector se apartó llamando a votar en blanco, y otro decidió participar de la Lista Marrón ${ }^{43}$ pero sin poner candidatos para la Comisión Directiva:

Nosotros seguíamos manteniendo el concepto del Peronismo de Base de que vos te burocratizás. Esa fue la equivocación del Sitrac-Sitram, se montan arriba y hacen la discusión entre cuatro paredes y no bajan hacia abajo. Fue el primer gremio clasista, pero para llegar al gremio clasista faltaba mucho, la base se tenía que convencer, tenía que tener conciencia. ${ }^{44}$

tadas, en lo posible, por los revolucionarios- [...]. También vemos la necesidad de romper con el oportunismo de PCR-PO, intentando obligarlos a levantar la declaración del 28 que ellos habían avalado. [...] Nuestra posición fue votada solamente por nuestros militantes". "Documento interno de un militante de El Obrero de Kaiser", El Obrero, 8 de mayo de 1972, p. 11.

42. "Fuera los agentes del gobierno y la patronal de nuestro gremio: Apoyo crítico al MRS-Lista Marrón", Núcleo de Activistas Clasistas del SMATA, 18 de abril de 1972. Espartaco en sus volantes se mostró incluso más crítico, planteando directamente que la Lista Marrón "no ha servido más que para ofrecer una alternativa burocrática de izquierda" y que "nadie puede asegurar que de triunfar esta lista sea cualitativamente distinta a la de Bagué". "Espartaco ante las elecciones del SMATA", Espartaco, 6 de abril de 1972. La caracterización del MRS y la Lista Marrón realizada por Carlos Mignon se basó en gran medida en los materiales producidos en este período por El Obrero y Espartaco (Mignon, 2014: 246-259). Vale aclarar que ambas corrientes posteriormente se autocriticaron de estas posiciones, definiéndolas como "superizquierdistas". Espartaco se integró al MRS poco después de su triunfo. "SMATA, La construcción de la dirección clasista”, Espartaco, junio de 1972. Y El Obrero entró en un proceso de discusión interna que, entre otras cosas, culminó con una "redefinición del clasismo" (Cormick, 2014). Cuando se sumó a la Lista Marrón de 1974 se autocriticó públicamente: "Nuestra organización ha pagado muy caro no tener en claro cómo se practica la unidad. Nosotros hace dos años atrás nos marginábamos de este proceso y posiblemente nos enfrentamos con nuestra posición a los trabajadores mecánicos, esta falta de claridad nos hizo caer en una posición sectaria que hoy autocriticamos". “SMATA: Vote Lista Marrón”, Periódico El Obrero, mayo de 1974.

43. Así lo consignó la revista Panorama en una nota sobre las elecciones del SMATA cordobés: "Un sector del peronismo de base -ubicado a la izquierda del peronismo combativo que inspira nacionalmente Julio Guillán y simpatizantes de Raimundo Ongaro- decidió votar en blanco; y otro sector de ese mismo bloque, más radicalizado aún, optó por aliarse con la izquierda". "Mecánicos: La victoria de la izquierda", Panorama, $\mathrm{n}^{\circ}$ 262, 4 al 10 de mayo de 1972, p. 25.

44. Entrevista a Juan Delgado, op. cit. Marcelo Raimundo afirma que el PB tenía cierto desprecio por los ámbitos sindicales que consideraba "superestructurales", poniendo 
Respecto del PRT-EC, Bohoslavksy refiere que "los activistas del PRT (o simpatizantes) participaron desde el inicio en la formación de la Marrón, pero eran minoritarios y siempre enfrentaron una dura resistencia de Salamanca, pero integraron la nueva directiva en puestos de segunda línea". ${ }^{45} \mathrm{Y}$ el propio Santucho, estando en prisión, escribió un boletín interno tras el triunfo de la Lista Marrón señalando las tareas de los militantes partidarios en el SMATA Córdoba (Mattini, 2003: 139).

Por su parte, los activistas del PC tardaron un tiempo en terminar de definirse. Según PO, fue "el fracaso de un frente con el oficialismo depurado" lo que los terminó volcando a participar en la Marrón. ${ }^{46}$ Efectivamente, para esta fuerza era incómoda la integración en una lista motorizada por fuerzas que caracterizaba como "ultraizquierdistas", a lo que se sumaba el hecho de que en ese momento a nivel provincial los gremios independientes estaban aliados con el peronismo legalista, que incluía a la conducción del SMATA. ${ }^{47}$

Finalmente, entonces, las organizaciones politicas de la izquierda que participaron de la Lista Marrón fueron el PCR, el PC, el PB, PO, VC y el PRT-EC. ${ }^{48}$ Pero, como constantemente se encargaban de remarcar sus dirigentes, la lista no era simplemente un acuerdo entre tendencias político-sindicales, sino un frente de delegados y activistas, con una gran cantidad de independientes, en el que intervenian las distintas tendencias. ${ }^{49}$

En el marco de la heterogeneidad de fuerzas presentes, dentro de la lista quedaron diferenciados dos grandes bloques. El primero, en-

el centro de su trabajo en la construcción de agrupaciones y la organización de las bases en cada sección y fábrica (2004: 119-121).

45. Comunicación personal con Abel Bohoslavsky, 23 de abril de 2015.

46. "Triunfo histórico en el SMATA cordobés", Política Obrera, n 108, 3 de mayo de 1972, p. 7.

47. Es ilustrativo que en el periódico del PC no apareciera ninguna nota sobre las elecciones del SMATA Córdoba en los meses previos a estas, y solo se publicara un breve balance posterior. "Estilo clasista y unitario en la victoria de la Lista Marrón", Nuestra Palabra, n ${ }^{\circ} 1141,16$ de mayo 1972, p. 7.

48. También los unificados PRT-LV y Partido Socialista Argentino -Secretaría Coraldieron su apoyo a la Lista Marrón, caracterizándola como una lista "de izquierda y combativa". "SMATA Córdoba: Los obreros votan a la izquierda", Avanzada Socialista, $\mathrm{n}^{\circ} 12,17$ de mayo de 1972 .

49. Así lo señalaba Salamanca: "El MRS no es patrimonio de ninguna agrupación. A su surgimiento contribuyen hombres de diversas tendencias, con la idea de no hacer un organismo partidista ni sectorial, sino echar las bases de un movimiento amplio. [...] En el MRS no existen las tendencias, sino hombres que militan en diversas tendencias, y un grueso de compañeros independientes". "Córdoba: la recuperación del SMATA", La Comuna, n 5, junio de 1972, p. 3. 
cabezado por Salamanca como candidato a Secretario General, estaba conformado por las agrupaciones clasistas vinculadas a la izquierda revolucionaria marxista (PCR, PO, VC, PRT-EC) junto con activistas peronistas e independientes de izquierda, $\mathrm{y}$, diferenciados pero cercanos, los militantes del Peronismo de Base. El otro, con el candidato a Secretario Gremial Hugo Rivero como principal referente, lo integraban los militantes del PC y el MUCS junto a activistas radicales, peronistas e independientes, muchos provenientes de la ex Lista Azul, y se ligaba al espacio gremial encabezado por Tosco.

Finalmente, la Lista Marrón quedó constituida como la expresión de una masa muy amplia de delegados y obreros combativos, encabezados por los activistas clasistas, que se oponían al torrismo desde definiciones antiburocráticas, antipatronales y antidictatoriales. Su programa hizo centro en la democracia sindical y en las reivindicaciones obreras postergadas, y se definió "contra las patronales, la Dictadura, los dirigentes traidores y conciliadores" y "por un sindicato de y para la clase obrera sin injerencia patronal ni estatal". ${ }^{50}$ Para la campaña apeló a la discusión y participación masiva de las bases mecánicas, con volantes diarios, alquilando un local y realizando asambleas en puerta de fábrica, y durante los días de la elección garantizó fiscales en todas las mesas y movilizó centenares de personas para el escrutinio.

El 28 de abril se conocieron los resultados: con una alta participación electoral, la Lista Marrón se impuso con 3.229 votos, contra 2.875 de la Lista Verde y Celeste del torrismo. ${ }^{51}$ Para las fuerzas que se referenciaban con el sindicalismo clasista, el triunfo era un gran paso adelante, y abria nuevas condiciones para lo que seguía siendo la tarea central: el desarrollo del clasismo entre las bases mecánicas. En ese sentido se pronunció Salamanca cuando, unos meses después del triunfo, le pidieron una caracterización de la nueva conducción:

Te diría que es clasista y reformista a la vez. Porque hay una alianza entre clasistas y reformistas donde ninguna de las dos corrientes tiene hegemonía. Factores como la práctica de la democracia sindical, la movilización y participación continua de la gente, la lucha interna contra la burocracia, ayudan a que se vaya avanzando a posiciones clasistas. Es claro que lo

50. "Los diez puntos de la Marrón”, MRS-Lista Marrón, en Politica Obrera, n 109, 10 de mayo de 1972, p. 5. Además de las consignas, la Lista Marrón publicó materiales fundamentando ampliamente los puntos citados. Ver en Nuevo Hombre, $\mathrm{n}^{\circ} 29,1$ de mayo 1972, p. 13.

51. "Elecciones: Mecánicos", Documentación e Información Laboral, n 147, mayo de 1970, p. 112. 
fundamental es la afirmación y desarrollo del clasismo en las bases obreras del SMATA; esto definirá el rumbo. ${ }^{52}$

\section{Consideraciones finales}

La izquierda fue un fenómeno siempre presente en el SMATA Córdoba, pero fue hacia fines de los 60, en el marco de la dictadura de Onganía, del debilitamiento del torrismo, de la radicalización política general y del surgimiento de las nuevas organizaciones de la izquierda revolucionaria, cuando esta cobró un nuevo impulso, constituyéndose como uno de los elementos clave que posibilitaron la construcción de una alternativa de dirección sindical.

En cuanto a la experiencia del SMATA Córdoba, la indagación pormenorizada sobre las distintas fuerzas presentes entre los mecánicos, sus orígenes, formas de inserción, influencia y posicionamientos era una cuenta pendiente. ${ }^{53}$ La gran cantidad de organizaciones registradas en este trabajo solo permitió realizar una primera aproximación sobre la actuación y las características específicas de cada una, lo que abre el camino para futuras indagaciones.

Al calor de la ofensiva de la dictadura y las patronales automotrices, de las grandes luchas protagonizadas por los mecánicos, como el Cordobazo y las ocupaciones fabriles de 1970, y de la influencia de Sitrac-Sitram, en esta fracción obrera fue cobrando fuerza una línea de acción sindical clasista. En la medida en que el torrismo fue entrando en crisis y descomposición se planteó la necesidad de una alternativa de dirección, y allí las organizaciones de izquierda que se referenciaban en la experiencia clasista de Fiat, junto con otras fuerzas y una gran cantidad de activistas independientes, jugaron un rol protagónico impulsando la constitución del MRS.

El período abordado, marcado por el GAN y la perspectiva de apertura electoral, fue un momento de definiciones, reelaboraciones e incluso de cambios programáticos para muchas de las organizaciones de la izquierda, y esto se plasmó también en cuanto a sus líneas de intervención en el movimiento obrero. En relación con esto, la experiencia de Fiat fue

52. "MRS y clasismo", La Comuna, no 7, diciembre de 1972, p. 5.

53. En este punto, creemos pertinente la observación realizada por Héctor Lobbe: "Hasta el momento, la historiografia ha eludido sistemáticamente sumergirse en la relación entre la izquierda revolucionaria y la movilización obrera a mediados de la década del 70. Sospechamos que tal actitud no responde únicamente a la dificultad en acceder a los documentos producidos por las diferentes organizaciones de izquierda. Por el contrario, pareciera que se intentara deliberadamente ignorar esa presencia y, aún más, el rol de conducción de fracciones avanzadas de la clase obrera" (Lobbe, 2009: 32). 
central, tanto porque mostró la posibilidad concreta de una dirección sindical clasista como por las lecciones que dejó su derrota. El balance crítico realizado por la mayoría de las organizaciones de la izquierda revolucionaria fue uno de los factores que llevaron a la consolidación del MRS como un movimiento amplio basado en posicionamientos antiburocráticos, antipatronales y antidictatoriales. Incluso las pocas fuerzas que rechazaron estas definiciones poco después se autocriticarian. Por lo tanto, las características y el programa de la Lista Marrón no encuentran su explicación en un "apoliticismo" o "moderación", sino que en última instancia fueron expresión tanto de las especificidades del proceso del SMATA, atendiendo al nivel de conciencia alcanzado por las bases y a las fuerzas politicas presentes, como también de las conclusiones sacadas en la izquierda respecto de la experiencia de Sitrac-Sitram.

Sin lugar a dudas, el triunfo de la Lista Marrón en uno de los sindicatos más importantes de la convulsionada provincia de Córdoba significó en su momento un gran salto para el sindicalismo clasista. Lejos de desaparecer tras el golpe sufrido con la derrota de Fiat, como pretendian la dictadura y el conjunto de las clases dominantes, el clasismo rápidamente se levantaba, abriendo nuevas perspectivas para su crecimiento en la clase obrera argentina.

\section{Bibliografia}

Balvé, Beba et al. (2006), Lucha de calles, lucha de clases: elementos para su análisis. Córdoba 1971-1969, Buenos Aires: Ediciones RyR-CICSO.

Basualdo, Victoria y Federico Lorenz (2012), "Los trabajadores industriales argentinos en la primera mitad de la década del 70: propuestas para una agenda de investigación a partir del análisis comparativo de casos", Páginas. Revista digital de la Escuela de Historia, UNR, año IV, $\mathrm{n}^{\circ}$ 6, Rosario, pp. 123-157.

Bergstein, Jorge (1987), El “Cordobazo". Memorias, testimonios, reflexiones, Buenos Aires: Cartago.

Bohoslavsky, Abel (2011), "Biografias y relatos insurgentes. La historia del PRT en la memoria de Abel Bohoslavsky", Sísifo, año I, n 1 , Buenos Aires.

Brennan, James P. (1996), El Cordobazo. Las guerras obreras en Córdoba, 1955-1976, Buenos Aires: Sudamericana.

Brennan, James P. y Mónica Gordillo (2008), Córdoba rebelde. El Cordobazo, el clasismo y la movilización social, La Plata: De la Campana.

Cangiano, María Cecilia (1993), "Pensando a los trabajadores: la historiografia obrera contemporánea argentina entre el dogmatismo y la innovación", Boletín del Instituto de Historia Argentina y Americana "Dr. Emilio Ravignani”, Tercera Serie, $n^{\circ}$ 8, Buenos Aires, pp. 117-132.

Campellone, José y Marisabel Arriola (2006), SMATA Seccional Córdoba. 50 años de vida, 50 años de lucha, Córdoba: M.E.L. Editor. 
Cormick, Federico (2014), "La Organización Comunista Poder Obrero y su perspectiva en el movimiento obrero. Una apuesta al clasismo: Del Sitrac Sitram a Villa Constitución”, en VIII Jornadas de Sociología de la $U N L P$, Buenos Aires.

Duhalde, Eduardo L. y Eduardo M. Pérez (2003), De Taco Ralo a la alternativa independiente. Historia documental de las Fuerzas Armadas Peronistas y del Peronismo de Base. Tomo 1: Las FAP, Buenos Aires: De la Campana.

Ferrero, Roberto (2009), Del mutualismo al Cordobazo. Breve historia del movimiento obrero de Córdoba, Córdoba: CEPEN.

González, Ernesto (coord.) (2006), El trotskismo obrero e internacionalista en la Argentina. Tomo 4: El PRT La Verdad, ante el Cordobazo y el clasismo, vol. 1, Buenos Aires: Fundación Pluma.

Gordillo, Mónica (1996), Córdoba en los 60. La experiencia del sindicalismo combativo, Córdoba: REUN.

Laufer, Rodolfo (2016), "El clasismo en el SMATA Córdoba. Ocupaciones fabriles, democracia sindical e izquierda clasista: la toma de la matricería Perdriel, mayo de 1970", Estudios del Trabajo, n 49, ASET, Buenos Aires, pp. 91-121.

- (2017a), "Clasismo y violencia obrera en el SMATA Córdoba. Las ocupaciones de Perdriel, 1970", Cuadernos de Marte, $\mathrm{n}^{\circ} 12$, Instituto de Investigaciones Gino Germani (UBA), Buenos Aires, pp. 117-145.

- (2017b), "Análisis crítico de las tesis de James Brennan sobre el clasismo cordobés", Conflicto Social, $n^{\circ} 18$, Instituto de Investigaciones Gino Germani (UBA), Buenos Aires, pp. 196-223.

Lobbe, Héctor (2009), La guerrilla fabril. Clase obrera e izquierda en la Coordinadora de Zona Norte del Gran Buenos Aires (1975-1976), Buenos Aires: RyR.

Lorenz, Federico (2007), Los zapatos de Carlito. Una historia de los trabajadores navales de Tigre en la década del setenta, Buenos Aires: Grupo Editorial Norma.

Mangiantini, Martín (2014), "Clase y partido. Surgimiento, proletarización y militancia fabril del PRT-La Verdad (1968-1972)", Archivos de Historia del Movimiento Obrero y la Izquierda, año II, $\mathrm{n}^{\circ}$ 4, Buenos Aires, pp. 31-52.

Mattini, Luis (2003), Hombres y mujeres del PRT-ERP: la pasión militante, Buenos Aires: De la Campana.

Menéndez, Héctor (2009), "El fracaso de la dirección obrera y las causas de la derrota después del Cordobazo", en Jornadas "A 40 años del Cordobazo", Córdoba.

Mignon, Carlos (2014), Córdoba obrera. El sindicato en la fábrica 1968-1973, Buenos Aires: Imago Mundi.

Ortiz, María Laura (2015), Violencia y represión. Los trabajadores clasistas en Córdoba, 1969-1976, tesis de doctorado inédita, FFyL-UBA, Buenos Aires.

Pacheco, Julieta (2013), "La regional cordobesa del Movimiento de Liberación Nacional (MLN): un caso de radicalización política como producto de la 
agudización de la represión dictatorial (1966-1969)", Historia, Voces y Memoria. Revista del Programa de Historia Oral, INDEAL-FFyL-UBA, n ${ }^{\circ}$ 6, Buenos Aires, pp. 155-183.

Pozzi, Pablo (2004), Por las sendas argentinas... El PRT-ERP. La guerrilla marxista, Buenos Aires: Eudeba.

Pozzi, Pablo y Alejandro Schneider (2000), Los setentistas. Izquierda y clase obrera (1969-1976), Buenos Aires: Eudeba.

Raimundo, Marcelo (2004), "Izquierda peronista, clase obrera y violencia armada: Una experiencia alternativa”, Sociohistórica, $\mathrm{n}^{\circ}$ 15-16, UNLP, pp. 99-128.

Rot, Gabriel (2016), "Un balance de los estudios sobre las Organizaciones Político-Militares argentinas", Archivos de Historia del Movimiento Obrero y la Izquierda, año V, nº 9, Buenos Aires, pp. 33-53.

Sánchez, Pilar (2008), El gordo Antonio. Vida, pasión y asesinato del dirigente comunista revolucionario César Gody Álvarez, Buenos Aires: Ágora.

Torres, Elpidio (1999), El Cordobazo. La historia, Buenos Aires: Catálogos. Werner, Ruth y Facundo Aguirre (2009), Insurgencia obrera en la Argentina, 1969-1976. Clasismo, coordinadoras interfabriles y estrategias de la izquierda, Buenos Aires: Ediciones IPS.

$* * *$

Titulo: Left and clasismo in the '70s. Debates about the Trade Union Recovery Movement - Brown List of SMATA Córdoba

Resumen: El presente artículo indaga sobre los orígenes y el desarrollo de las distintas organizaciones de izquierda presentes entre los trabajadores mecánicos del SMATA Córdoba a inicios de los 70: Partido Comunista Revolucionario, Partido Comunista, Peronismo de Base, Politica Obrera, Vanguardia Comunista, Partido Revolucionario de los Trabajadores, El Obrero y Espartaco. En particular, analiza sus posicionamientos y debates en torno a la construcción del Movimiento de Recuperación Sindical - Lista Marrón, que llegó a la conducción sindical en abril de 1972. De esta forma, muestra el importante rol que la izquierda jugó en la construcción de una alternativa a la dirección sindical encabezada por Elpidio Torres, referente del peronismo vandorista, y analiza cómo impactó en este proceso el balance realizado sobre la experiencia clasista de Sitrac-Sitram.

Palabras clave: clasismo - izquierda - SMATA - Córdoba

Abstract: This paper explores the origins and development of the different or-
ganizations of the left present among the mechanic workers of SMATA Córdoba
in the early 70's: Partido Comunista Revolucionario, Partido Comunista, Per-
onismo de Base, Politica Obrera, Vanguardia Comunista, Partido Revolucionario
de los Trabajadores, El Obrero y Espartaco. Specifically, it analyzes its positions
and debates around the construction of the Trade Union Recovery Movement -
Brown List, which won the union leadership in April 1972. In this way, it shows
the key role played by the left in the construction of an alternative to the trade 
union leadership led by the peronista vandorista Elpidio Torres, and analyzes how the conclusions drawn on the clasista experience of Sitrac-Sitram impacted in this process.

Keywords: clasismo - left - SMATA - Córdoba

Recepción: 24 de junio de 2017. Aprobación: 12 de diciembre de 2017. 